\title{
The Impact of Electronic Commerce Risk on the Effectiveness of Electronic Banking Services. A Field Study of Several Commercial Banks In The Province of Nineveh
}

\author{
Assist Lecturer Jasim M. Hasso, Lecturer Mohammed Hussein Al-Sawaf, Assist \\ Lecturer Bakr A. Saleh \\ Jalhass050@ntu.ntu.iq, mohamad.h.sawaf@ntu.edu.iq ayoob.b.2016@ntu.edu.iq.
}

\author{
NORTHERN TECHNICAL UNIVERSITY, MOSUL, IRAQ
}

\begin{abstract}
The study aims to highlight the role of e-commerce in the world of trade and banking services as one of the most widespread and least expensive means, especially after the internet became available to many categories, people and organizations meaning easy access to a large number of customers in return for recognizing the existence of many risks. These activities are accompanied by the need for appropriate precautionary measures to minimize these risks. The statistical analysis method (SPSS) was used to analyze the results of the field study on the research community and its sample represented by several commercial banks in the province of Nineveh.

The researchers recommended the need for commercial banks to understudy and introduce advanced technologies and be constantly updated as well as periodically changing passwords for individuals working, to protect their information systems from hackers and unauthorized access.
\end{abstract}

Keywords: e-commerce, commercial banks, and e-banking services.

A. Introduction: E-commerce has become a reality in an environment characterized by a changing and highly complex nature and contains a lot of risks resulting from the use of modern technologies. Commercial banks have to cope with that reality and keep pace with the changes and developments with the need for procedures and measures to reduce risks. This significantly affects the reputation of banks among their competitors as well as the resulting financial losses which can often lead to bankruptcy. Therefore, the problem of research is to identify the risks resulting from the use of electronic commerce tools in the provision of electronic banking services.

To achieve the objectives and hypotheses of the research, the research was divided into three topics, the first section included the research methodology, while the second section explains the concept of electronic commerce, its components, the changes they have caused in the business environment, the concept of commercial banks, types of banking services and the risks to commercial banks in the electronic commerce environment. The third section deals with the field study of several private commercial banks in the province of Nineveh, and finally conclusions and recommendations.

\section{Research problem:}

E-commerce has contributed and continues to develop and change the structure of global trade through the continuous change in modern technologies. This has made the parties of the 
commercial relationship closer and business deals more appropriate and the level of profitmaking more since commercial banks constitute a large and effective part in financing global trade. In light of the fierce competition from its peers, it should keep abreast of these changes and developments. The problem of research is the following questions:

a. What are the risks resulting from the use of electronic commerce tools towards the effectiveness of electronic banking services provided by commercial banks?

b. What are the procedures and measures to be taken to avoid the risks arising from the use of electronic commerce tools when providing electronic banking services?

\section{The Importance Of Research:}

The importance of research comes from the role of electronic commerce, which has become a highly complex environment characterized by a lot of risks resulting from the use of modern technologies. Therefore, commercial banks must keep pace with the reality of the changes resulting from the globalization, deregulation and liberalization of capital movement as well as the recent and accelerated developments in the world of information and communication technology. There is a need for procedures and measures to reduce those risks.

\section{Research Objectives:}

The research seeks to highlight the role of electronic commerce in the world of trade and banking services as one of the most widespread and least expensive means. This is especially after the internet became available to many categories of people and organizations, which means easy access to a large number of customers. Due to the risks associated with these activities, there is a need for appropriate precautionary measures to minimize those risks.

\section{Research Hypothesis:}

The research is based on the following two hypotheses:

a. There are many risks associated with the use of electronic commerce tools towards the effectiveness of electronic banking services provided by commercial banks.

b. Many procedures and measures can be taken to reduce the risks arising from the use of electronic commerce tools when providing electronic banking services.

\section{B. Literature Review}

This paper deals with the concept of electronic commerce and the most important components and changes it has made in the world of finance and business. It outlines the concept of commercial banks and the most important e-banking services provided by those banks to their customers. Modern technologies in the field of information and communication technologies are discussed, as well as the most important risks to those banks when providing banking services. Therefore, the research will not focus on e-commerce in particular, but in the use of banks for the mechanisms used electronically in the provision of banking services.

E-commerce: E-commerce can be defined as "the sale, purchase, transfer or exchange of products (goods, services, information) and other economic events that take place electronically via the internet, whether between organizations, between organizations and their customers or between organizations and government departments using information and communication technologies" [1]. 
It can also be defined as "any commercial operation between two or more parties to which the Internet has contributed wholly or in part, such as obtaining information about a particular good or service for the subsequent acquisition, whether by electronic payment or cash on delivery [2]

The Components Of Electronic Commerce: Electronic commerce depends on several components, most notably the following [3]:

- Infrastructure and wide dissemination of the internet must be provided so that it can reach the largest possible segment of consumers while providing the necessary tools and technical means to maintain the confidentiality of commercial transactions and to ensure the rights of all parties.

- Selecting people who have talent in the field of shopping and online trading. This will increase the percentage of sales and profits significantly by surveying them in the field of technology, software and human resources in commercial banks, whether large or medium.

- The state shall encourage electronic commerce and protect the rights of consumers and merchants, which is to put in place some clear legislations that prevent electronic piracy against financial activities carried out via the internet. This is very important because it encourages the use of this type of trade, as well as providing legal support and facilities for business owners who deal through e-commerce by encouraging investment in these areas which will benefit the national economy.

- Spreading scientific and cultural awareness among citizens and teaching them the right way through modern technologies while providing protection to the customer and the merchant from fraud so that there is mutual trust between the two parties when dealing through electronic commerce.

\section{Changes Brought About By E-Commerce In The Business Environment:}

E-commerce has brought many changes in the business environment, most notably the following [4]:

- Organization Structure: E-commerce has radically changed the structure of organizations. They must contain the mechanisms that enable them to pursue the process especially in light of internet hackers.

- Location of the Business: The geographic location of the organization is no longer important in the context of e-commerce. With modern technologies, anyone from anywhere in the world can complete the bulk of the transaction with a quick press of a computer keyboard. E-commerce organizations are experiencing breakthroughs that are not discovered until it is too late.

- $\quad$ Relationship with Partners and Customers: In the traditional approach, the relationship with partners and customers was a direct relationship, but under electronic commerce, the relationship became a relationship of a digital technical nature which may be manipulated.

- Payment Mechanism: Payment Processes have changed since payments can be made via the internet. However, this process is fraught with many risks, especially when hackers can use the accounts of third parties to make purchases. Cancellation of transactions can be impossible.

- Multi-Selling: In the field of traditional trade many people are qualified to do the sale and marketing process, but with the use of e-commerce many systems make sales based on 
pre-prepared software. The problem is that these programs lack human intelligence and may be manipulated by others.

- Distribution Channels: In the traditional trading environment, the marketing and distribution channels of the organizations' products are clearly defined and uncomplicated, which makes it easy to deal with.

- Calculation and Payment of Taxes: There are a large number of questions raised about the basis on which profits from transactions through e-commerce are subject to income taxes. The many difficulties related to the follow-up of these deals where many of them are concluded through the internet without a documenting copybook. They are executed and delivered electronically via the internet without entering the stores or passing through the customs outlets leading to evasion of taxes due to e-commerce operations.

Commercial Banks: Commercial banks are one of the most important pillars of the structure of the banking system. Commercial banks can be defined as "banks that accept deposits ondemand or for limited periods and engage in financial financing activity leading to the realization of development plans and support the national economy through savings and financial investment operations internally and externally, including contributing to the financing of projects and the required banking activities [5].

Banking Services Provided By Commercial Banks: The banking services provided by commercial banks are based on the ideas of the economist Adam Smith in his book (The Wealth of Nations), which outlines that banks provide credit services and maintain cash for a period not exceeding one financial year. Significant progress in the banking industry and the use of modern technologies for electronic commerce led to the expansion and increase of the services provided by commercial banks [7].

This is the research approach to the field of electronic banking provided by commercial banks as well as the risks associated with it, which can be explained as follows:

1.The Concept Of E-Banking Services: Technological development is one of the most important factors that contributed in changing the traditional activity of banks and shifting towards technical activity and providing services to customers through the expansion of the use of tools and techniques of e-commerce. This saves a lot of effort, time and money as well as achieving greater profits and financial returns. Thus, it can be defined as "the provision of traditional or innovative banking services through the use of open electronic means of communication, to enhance its market share, to reduce costs, or as a means of expanding its activities within and outside national borders [8].

2.Types Of Electronic Banking Services: Electronic banking services include many types, which can be explained as follows:

a. Information Services: This means the provision, marketing and presentation of traditional products and services offered by the bank electronically to customers using the bank's website without the bank incurring costs or risks that may affect its credibility towards customers.

b. Communications Services: This service allows customers to access the bank's internal information systems and network, which may result in the risk of changing or 
manipulating data and information, such as obtaining a statement of account for a customer or requesting credit facilities.

c. Executive services: This means services that allow the customer to access the bank's internal systems and access banking services through the internet such as conducting financial transfers or paying some bills from his account and these services are one of the most serious cases that the bank may face. Especially for hackers who can penetrate customer accounts and use for their purposes without being detected until after some time may be difficult to track and detect unauthorized access.

c. Advanced Services: This type of services includes opening new bank accounts for an existing customer and checks deposited for collection purposes, accessing and managing personal accounts, transferring between client's accounts inside and outside the bank, requesting bank loans, managing investment portfolios, and requesting letters of guarantee.

3. Advantages Of Electronic Banking: Electronic banking has several features which can be summarized as follows [14]:

- Services carried out remotely and without direct communication between service parties.

- Services that know no boundaries or geographical locations.

- Services based on virtual contracting without paper documents.

- Payment is made by currency or so-called electronic money.

Risks To Commercial Banks: Commercial banks face many risks in the provision of their electronic banking services. These risks vary and intertwine between the internal and external environment within which banks operate. From the viewpoint of researchers, the risks can be divided into two types of agencies:

1. Operational Risk: This type of risk is due to the following reasons:

a. Insufficient insurance systems: This type is attributed to the risks of unauthorized access to the bank's accounts systems to access and exploit customer information or steal credit card numbers in cooperation with parties inside or outside the bank.

b. Inadequate systems design or efficiency of implementation: This type of risk is due to the failure of the systems or inefficiency to meet the requirements of users and slowness in addressing problems as well as the lack of effective systems to protect the databases of customers.

c. Misuse by customers: This type of risk arises because of the lack of awareness of customer's precautionary security measures or allowing some criminal access to the accounts of other customers and accounts being exploited for fraud or theft of the contents of personal accounts.

2. Risks Of Banking Information Systems: This is the main pillar of the banking business and without providing the means of security and protection for these systems, the effects would undoubtedly lead to serious losses that no bank could bear as outlined below: [12]

\section{A. In Terms Of Source:}


- Internal Risks: As the employees of the bank are the main cause of this type of risk, these risks can occur in the stage of programming and design of the system or through data entry for the system to be processed and may be intentional or unintentional.

- External Risks: Risks that come from external threats such as hackers or competitors in the market who seek to obtain confidential information about the bank to exploit in the competition.

- Environmental risks: These are the risks that occur because of external forces against the will of man, such as natural disasters (earthquakes, storms, floods, etc.), or due to fluctuations in temperature and humidity that may cause damage to the system's hardware in part or whole.

\section{B. In Terms Of Intentional:}

- Intentional: It is the deliberate manipulation of data or information by a person or persons to destroy it or make unauthorized changes.

- Unintended: It is the errors of people because of ignorance and inadequate experience such as entering data in the wrong way or omissions and considered less harmful.

\section{In Terms Of Damage Resulting From Risks:}

- Physical Damage: The risk of damage or significant damage to any part of the system such as data storage devices, computers, etc., which are caused by human or natural disasters.

- Technical and logical: such as the introduction of viruses or malware to the system that leads to data corruption or theft.

\section{Procedures To Reduce The Risks To Banks When Offering Electronic Services:}

1. Confirming confidence in the bank's website: This means the approval of one of the accounting and auditing offices to confirm the management's assurance that the business applications in the bank's website are safe and reliable and can be used. For the bank to obtain that certificate, it must meet the following three condition[11]

Disclosure of the Nature of the Business: The bank should announce its policy through its website, which enables customers to deal with it per the policies announced on its website.

- The integrity of Operations: this means that the bank provides mechanisms to contribute to the provision of banking services to customers and at the prices announced through its website.

- Protection of Privacy and Information: It is the bank's responsibility to provide a complete protection system for the information of the client from any penetration and prevent the leakage of customer information to any unauthorized access.

2. Security Controls: The bank's management should take several measures to protect data and information within the bank's information systems, which requires them to provide a reasonable degree of protection and security (Qatar Central Bank: 2008: 257-258).

- Confidentiality and Unity of Information: Appropriate measures should be taken to maintain the confidentiality and integrity of the bank's information and records and its customers in a manner consistent with the confidentiality of such information that is 
transferred and stored in databases and is protected from unauthorized access. They also need to select encryption methods that ensure that such information is not compromised and stolen. There is a need to subject the procedures for the creation, storage and distribution of administrative levels to tight control and change them periodically and put appropriate security precautions for data stored on the site server.

- Customer Protection and Authentication Procedures: Necessary measures must be taken to ensure the authenticity of the customer's identity and verify the legitimacy of any access to the electronic system of the bank and audit to search for errors and illegal activities such as fraud. Customers need to be educated so that they know not to use the same phone number or their date of birth for their passcode and the need to change it continuously and avoid the use of unsecured computers, especially in public places. They also need to communicate continuously with the bank's management on the advice and guidance to be taken when dealing with modern technological developments used by the bank in providing its services to its customers.

- Determining the Powers and Separation of Responsibilities: There is a necessity to determine the powers and responsibilities of the employees working in the bank with the assurance that one of the employees is not alone in conducting, approving and executing operations.

- Precautionary policies and procedures: Policies and procedures should be put in place to provide security and protection to the bank's website as well as the accounting and financial information system. This would include firewalls that protect against unauthorized piracy or access. Anti-virus programs must be used and constantly updated to prevent data destruction or deletion. Security and risk insurance should be provided by legally recognized insurance companies.

\section{Survey Study}

To achieve the objectives of the research plan, the researchers prepared the questionnaire and distributed it to the research community and its sample, which is represented by several commercial banks in the province of Nineveh.

\section{Determine the research community}

The research community is represented by a selected sample of commercial banks in Nineveh Governorate, where 40 questionnaires were distributed to the respondents, of which (30) were received, which represents $75 \%$ of the distributed forms as shown in table 1:

Table 1: Percentage of respondents from each bank

\begin{tabular}{|l|l|l|}
\hline Units & Number & Percentage \\
\hline Jehan bank & 7 & $23 \%$ \\
\hline Assur Bank & 8 & $27 \%$ \\
\hline Middle East Investment Bank & 8 & $27 \%$ \\
\hline Gulf Bank & 7 & $23 \%$ \\
\hline
\end{tabular}




\begin{tabular}{|l|l|l|}
\hline Total & 30 & $100 \%$ \\
\hline
\end{tabular}

\section{Data Analysis}

Reflected in Table 2 are the answers of the respondents to the questions on the first hypothesis; "There are many risks associated with the use of electronic commerce tools towards the effectiveness of electronic banking services provided by commercial banks."

Table 2. Analysis of the results of the questions on the first hypothesis

\begin{tabular}{|c|c|c|c|c|}
\hline $\begin{array}{c}\text { Question } \\
\text { Number }\end{array}$ & $\begin{array}{c}\text { Arithmetic } \\
\text { Mean }\end{array}$ & $\begin{array}{c}\text { Standard } \\
\text { Deviation }\end{array}$ & $\begin{array}{c}\text { Difference } \\
\text { Factor }\end{array}$ & $\begin{array}{c}\text { Response } \\
\text { Ratio }\end{array}$ \\
\hline 1 & 4.5667 & 0.50401 & $11.04 \%$ & $91.33 \%$ \\
\hline 2 & 4.4333 & 0.56832 & $12.82 \%$ & $88.67 \%$ \\
\hline 3 & 4.2000 & 0.40684 & $9.69 \%$ & $84.00 \%$ \\
\hline 4 & 4.3000 & 0.65126 & $15.15 \%$ & $86.00 \%$ \\
\hline 5 & 3.8333 & 0.91287 & $23.81 \%$ & $76.67 \%$ \\
\hline Overall Index & 4.2667 & 0.60866 & $14.27 \%$ & $85.33 \%$ \\
\hline
\end{tabular}

It is noted from Table 2 that the total index of the respondents' strength was $85.33 \%$ with a mean of $4.26 \%$ which is very good and exceeded the accepted measurement tool (3) with a standard deviation of 0.60 versus the coefficient of difference $14.27 \%$. This indicates that the responses of the respondents were positive towards the first part of the first hypothesis.

Table 3 - Analysis of the results of the second part of the first axis of the first hypothesis related to the risks of banking information systems.

\begin{tabular}{|c|c|c|c|c|}
\hline Question Number & $\begin{array}{c}\text { Arithmetic } \\
\text { Mean }\end{array}$ & $\begin{array}{c}\text { Standard } \\
\text { Deviation }\end{array}$ & $\begin{array}{c}\text { Difference } \\
\text { Factor }\end{array}$ & $\begin{array}{c}\text { Response } \\
\text { Ratio }\end{array}$ \\
\hline 1 & 4.5667 & 0.62606 & $13.71 \%$ & $91.33 \%$ \\
\hline 2 & 4.4333 & 0.62606 & $14.12 \%$ & $88.67 \%$ \\
\hline 3 & 4.3333 & 0.66089 & $15.25 \%$ & $86.67 \%$ \\
\hline 4 & 4.4000 & 0.49827 & $11.32 \%$ & $88.00 \%$ \\
\hline 5 & 4.1333 & 0.68145 & $16.49 \%$ & $82.67 \%$ \\
\hline 6 & 4.0667 & 0.69149 & $17.00 \%$ & $81.33 \%$ \\
\hline
\end{tabular}




\begin{tabular}{|c|c|c|c|c|}
\hline 7 & 4.1667 & 0.59209 & $14.21 \%$ & $83.33 \%$ \\
\hline Overall Index & 4.3000 & 0.62519 & $14.54 \%$ & $86.00 \%$ \\
& & & & \\
\hline
\end{tabular}

It is noted from Table 3 that the total index of the respondents' strength was $86 \%$ with a mean of $4.300 \%$ which is very good and exceeded the accepted measurement tool (3) and standard deviation 0.625 versus the coefficient difference of $14.54 \%$ which indicates that the answers of the respondents were positive towards the second part of the first hypothesis.

Table 4 Analysis of the relationship between operating system risks and banking information systems risks in light of electronic commerce and the effectiveness of electronic banking services.

\begin{tabular}{|c|c|c|c|c|c|c|c|}
\hline $\begin{array}{c}\text { Risks / } \\
\text { Effectiveness of } \\
\text { e-banking } \\
\text { services }\end{array}$ & \multirow{2}{*}{ link } & \multicolumn{2}{|c|}{ influence } & \multirow{2}{*}{ R2 } & \multicolumn{2}{|c|}{ F } & \multirow{2}{*}{ moral level } \\
\cline { 1 - 6 } & & B0 & B1 & & computed & tabular & \\
\cline { 3 - 7 } $\begin{array}{c}\text { Relationship and } \\
\text { Impact }\end{array}$ & 0.597 & 2.793 & 0.912 & 0.36 & 15.469 & 4.2 & 0.001 \\
\hline
\end{tabular}

Based on the results in table 4 , it is clear that there is a positive correlation and significant significance between the operating system and banking information system risks and the effectiveness of electronic banking services, where the simple correlation coefficient between them is 0.597 , as well as a statistical significance between the risks in the light of electronic commerce The effectiveness of e-banking services is calculated as the calculated value of $\mathrm{T}$ (3.937), which is reinforced by the value of the coefficient of determination $\left(\mathrm{R}^{2}\right)$ of $35.6 \%$ which indicates that the independent variable (operational risk) accounts for $35.6 \%$ of the variance in the dependent variable. E-Banking Effectiveness (The remaining percentage) is the calculated value $F(15.469)$ and is greater than the table $F$ value (4.20), which indicates that there are statistical differences between operating system risks and the effectiveness of electronic banking services at the statistical significance level of 0.05 and the degree of freedom of 1.29.

Therefore, it accepts the hypothesis that "there are many risks associated with the use of electronic commerce tools towards the effectiveness of banking services provided by commercial banks."

Answers of the respondents to the second axis questions on the hypothesis, "There are many procedures and measures that can be taken to reduce the risks arising from the use of electronic commerce tools in the provision of electronic banking services" are shown in table 5.

Table 5 Analysis of the answers of the respondents to the second axis questions on the hypothesis 


\begin{tabular}{|c|c|c|c|c|}
\hline Question Number & $\begin{array}{c}\text { Arithmetic } \\
\text { Mean }\end{array}$ & $\begin{array}{c}\text { Standard } \\
\text { Deviation }\end{array}$ & $\begin{array}{c}\text { Difference } \\
\text { Factor }\end{array}$ & $\begin{array}{c}\text { Response } \\
\text { Ratio }\end{array}$ \\
\hline $\mathbf{1}$ & $\mathbf{4 . 6 0 0 0}$ & $\mathbf{0 . 7 2 3 9 7}$ & $\mathbf{1 5 . 7 4 \%}$ & $\mathbf{9 2 . 0 0 \%}$ \\
\hline $\mathbf{2}$ & $\mathbf{4 . 2 0 0 0}$ & $\mathbf{1 . 0 9 5 4 5}$ & $\mathbf{2 6 . 0 8 \%}$ & $\mathbf{8 4 . 0 0 \%}$ \\
\hline $\mathbf{3}$ & $\mathbf{4 . 3 3 3 3}$ & $\mathbf{0 . 8 4 4 1 8}$ & $\mathbf{1 9 . 4 8 \%}$ & $\mathbf{8 6 . 6 7 \%}$ \\
\hline $\mathbf{4}$ & $\mathbf{4 . 7 6 6 7}$ & $\mathbf{0 . 5 4 0 1}$ & $\mathbf{1 0 . 5 7 \%}$ & $\mathbf{9 5 . 3 3 \%}$ \\
\hline $\mathbf{5}$ & $\mathbf{4 . 5 3 3 3}$ & $\mathbf{0 . 6 2 8 8 1}$ & $\mathbf{1 3 . 8 7 \%}$ & $\mathbf{9 0 . 6 7 \%}$ \\
\hline $\mathbf{6}$ & $\mathbf{4 . 5 6 6 7}$ & $\mathbf{0 . 7 2 7 9 3}$ & $\mathbf{1 5 . 9 4 \%}$ & $\mathbf{9 1 . 3 3 \%}$ \\
\hline $\mathbf{7}$ & $\mathbf{4 . 6 0 0 0}$ & $\mathbf{0 . 6 2 1 4 6}$ & $\mathbf{1 3 . 5 1 \%}$ & $\mathbf{9 2 . 0 0 \%}$ \\
\hline $\mathbf{8}$ & $\mathbf{4 . 7 0 0 0}$ & $\mathbf{0 . 5 3 4 9 8}$ & $\mathbf{1 1 . 3 8 \%}$ & $\mathbf{9 4 . 0 0 \%}$ \\
\hline $\mathbf{9}$ & $\mathbf{4 . 7 6 6 7}$ & $\mathbf{0 . 5 0 4 0 1}$ & $\mathbf{1 0 . 5 7 \%}$ & $\mathbf{9 5 . 3 3 \%}$ \\
\hline $\mathbf{1 0}$ & $\mathbf{4 . 4 0 0 0}$ & $\mathbf{0 . 6 7 4 6 6}$ & $\mathbf{1 5 . 3 3 \%}$ & $\mathbf{8 8 . 0 0 \%}$ \\
\hline $\mathbf{1 1}$ & $\mathbf{4 . 2 3 3 3}$ & $\mathbf{0 . 7 2 7 9 3}$ & $\mathbf{1 7 . 2 0 \%}$ & $\mathbf{8 4 . 6 7 \%}$ \\
\hline Overall index & index 4.5182 & 0.68976 & $15.27 \%$ & $90.36 \%$ \\
\hline
\end{tabular}

It is noted from Table 5 that the total index of the respondents' strength was $90.36 \%$ with a mean of $4.518 \%$ which is very good and exceeded the accepted measurement tool (3) with a standard deviation of 0.668 versus the coefficient of variation $15.27 \%$ which indicates that the answers of the respondents were positive towards the second part of the first hypothesis.

Table 6 The analysis of the relationship and impact between the two dimensions (risks of operating systems and banking information systems) and the measures and measures that can be taken in the light of electronic commerce in the provision of electronic banking services.

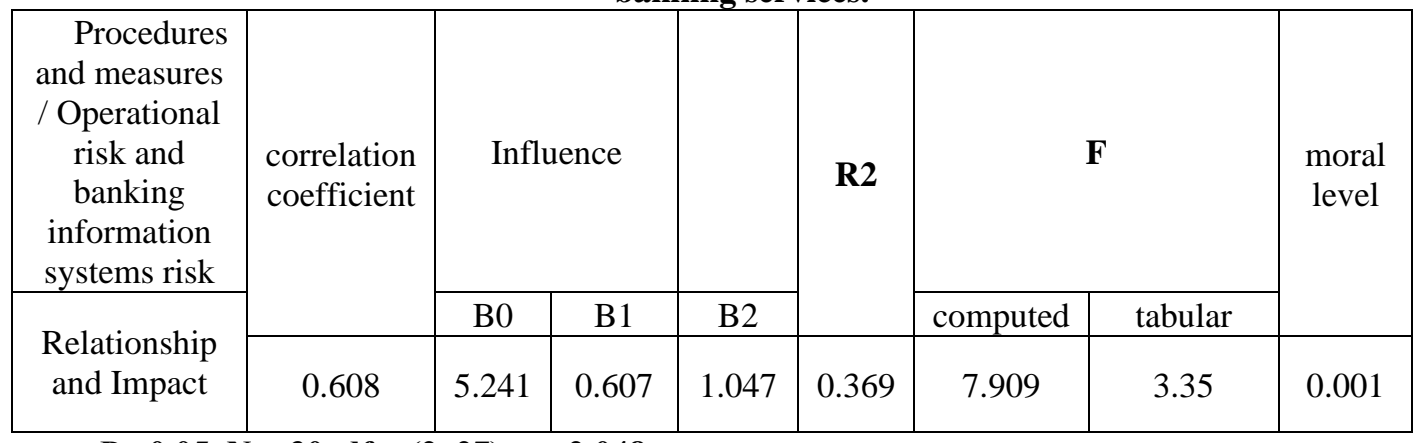

$P \leq 0.05, N=30, d f=(2,27), t=2.048$ 
Based on the results of table 6 , it is clear that there is a positive correlation and significance between operational system risks and banking information systems risks and the procedures and measures that can be taken in the light of electronic commerce when providing electronic banking services. The statistical value of $\mathrm{T}$ was calculated as 4.052 , which is reinforced by the value of the coefficient of determination $\left(\mathrm{R}^{2}\right)$ of $36.9 \%$, which indicates that the two independent variables (operational risk and the risk of banking information systems) explain $36.9 \%$. The effectiveness of the services (the remaining $63.1 \%$ is due to other factors). The calculated $\mathrm{F}$ value (15.469) is greater than the table $\mathrm{F}$ value (4.20). This indicates that there are statistical differences between the operating system and banking information system risks and the effectiveness of services. Electronic banking is at the statistical significance level of 0.05 and the degree of freedom $(1,29)$, so the hypothesis is accepted that "there are many risks associated with the use of electronic commerce tools towards the effectiveness of banking services provided by commercial banks."

\section{Conclusions and recommendations}

\section{A. Theoretical side conclusions:}

1. Commercial banks are considered one of the most important pillars of the financial system of any country which actively contributes effectively to the development of the national economy by providing the necessary financing for companies and customers.

2. Electronic banking services have become an urgent necessity in a world characterized by change and development in various fields, especially in the field of electronic commerce and modern technologies that reduce time and effort in providing banking services with high quality and the lowest costs.

3. Despite the advantages provided by electronic banking services, which reflect positively on the satisfaction of customers and companies, it is fraught with many risks.

\section{B. The Practical Aspect:}

1. The majority of respondents agreed (85.33\%) with an arithmetic mean of (4.266) on the existence of many risks associated with the use of electronic commerce tools towards the effectiveness of electronic banking services provided by commercial banks.

2. The majority of respondents agreed $(90.36 \%$ ) with a mean of 4.518 on the existence of many procedures and measures that can be taken to reduce the risks arising from the use of electronic commerce tools when providing electronic banking services.

3. There is a positive correlation and significant correlation between operating system risks and banking information systems risks and the effectiveness of electronic banking services, where the simple correlation coefficient between them is 0.597 .

4. There are statistical differences between operating system risks and the effectiveness of electronic banking services at the statistical significance level (0.05) because the calculated F value (15.469) is greater than the tabular value of $F(4.20)$.

\section{Recommendations}

1. There is a need for commercial bank understudies to introduce advanced technologies and constantly update to protect their information systems from information hackers.

2. There is a need for a periodic change of passwords for individuals working in the field of information systems. 


\section{References}

[1] Shaheen, Ayman Ahmed Mohammed 2013, The elements of electronic banking as a tool for the promotion and development of payment systems and electronic commerce. Master Thesis, Faculty of Commerce, Islamic University, Gaza, Palestine

[2] Scfali, Dalila and Sudani, Samira, 2011. The appropriateness of accounting systems for the E-Commerce Environment, Master Academy Note, Faculty of Economics and Management Sciences, University od Venturi, Constantine, Algeria

[3] Nirvana, 2018, an article entitled the elements of e-commerce, published on the website of the messenger, the date of visit by the researcher - 3/7/2019 https://www.almrsal.com/post/667638.

[4] Muheisen, Sabreen Sobhi Hussein, 2017, the suitability of the accounting profession to the e-commerce environment in accordance with the requirements of IAS 18 "Revenue Recognition" "A Field Study on Local Banks Operating in Palestine" Master Thesis, Faculty of Commerce, Islamic University, Gaza, Palestine.

[5] Kamal, Youssef, 2013, definition of commercial banks and their most important advantages, an article published on the Internet, the Arab Accountant Forum website, https://accdiscussion.com/acc7012.html.

[6] Al-Janabi, Nabil Mahdi Kadhim and Al-Shibawi, Amal Shaker Cancun, the role of commercial banks in activating the activity of the Iraq Stock Exchange, a research drawn from a master's researcher Amal Shaker, College of Management and Economics, University of Qadisiyah, Iraq. http://qu.edu.iq/repository/wp-content/uploads/2017/.

[7] Mansouri, Ruqaya and Abdelmalek, Asmaa, 2014, Electronic Banking, Graduation Memorandum for Bachelor Degree, Faculty of Economic Sciences, Management and Commercial Sciences, Abou Bakr Belkaid University, Algeria.

[8] Fahd, Nasr Hamoud Muznan, 2011, the potential for the transition towards electronic banking in the Arab countries, Journal of the Faculty of Management and Economics, University of Karbala, No. 4 for 2011.

[9] Al-Atra, Daghnoush, 2017, Using the Internet as a tool to provide banking services and its impact on the state of banking performance, $\mathrm{PhD}$ dissertation, Faculty of Economic Sciences and Management Sciences, University of Mohammed Khader, Algeria.

[10]Al-Huraishh, Ali Mohammed, Effect of Quality of e-Banking Services on Customer Satisfaction - An Empirical Study on Memo Saudi Fransi Bank in Syria, Master Thesis, Virtual University, Syria.

[11] Abu Mahadi, Sanaa Taleb Abdul Karim, 2017, The Effect of Reliability of Accounting Information Systems on Banking Performance Indicators, An Empirical Study on Local Banks Operating in Palestine, Unpublished Master Thesis, Faculty of Commerce, Islamic University, Gaza, Palestine. 
[12]Hamid, Mohammed Dabbas and Nino, Marco Ibrahim, 2007, the protection of information systems, without edition, Dar Al-Hamed for publication and distribution, Amman Jordan.

[13] Wadi, Rushdie Abdel-Latif, 2008, The Importance and Benefits of Electronic Banks in the Gaza Strip in Palestine and the Obstacles of Their Spread, Islamic University Journal for Humanitarian Research, Vol. 16, No. 2, Gaza.

[14]Draghi, Oum El Kheir, 2015, The Impact of Modernization of Banking Services on the Banking Performance - Case Study of the Algerian External Bank from 2008 to 2013 - Unpublished Master Thesis, Faculty of Economic Sciences, Commercial Sciences and Management Sciences, Kasidi Merbah University, Ouargla, Algeria. 